\title{
Desenvolvimento de um radioimunoensaio de dexametasona no soro como subsídio para o diagnóstico da sindrome de Cushing
}

\author{
Development of serum dexamethasone radioimmunoassay to corroborate Cushing's syndrome diagnosis
}

Lilian Fukusima Hayashi'; Keiko O. Noguti²; Odete H. Nakamura ${ }^{3}$; Claudio Elias Kater ${ }^{4}$ José Gilberto Henrique Vieira ${ }^{5}$

unitermos
Dexametasona
Cortisol
Radioimunoensaio
Teste de supressão
Síndrome de Cushing

\section{resumo}

Introdução: $\mathrm{O}$ teste de supressão com $1 \mathrm{mg}$ de dexametasona (TSDx) é amplamente empregado no rastreamento da síndrome de Cushing (SC) dada sua elevada acurácia diagnóstica. A SC é um distúrbio endocrinometabólico resultante do hipercortisolismo crônico com característica de ausência de supressão do cortisol no TSDx. Objetivo: Desenvolver um radioimunoensaio (RIE) para a dosagem de dexametasona ( $\mathrm{Dx}$ ) no soro para complementar o TSDx. Métodos: Foram imunizados três coelhos com o conjugado dexametasona-21-hemissuccinato-BSA para escolha do melhor anticorpo e o RIE foi desenvolvido de acordo com as recomendações da RE 899/2003 da Agência Nacional de Vigilância Sanitária (ANVISA). Analisamos 96 voluntários, sendo 67 submetidos ao TSDx e 29 não, e 12 pacientes com SC, estudados na Universidade Federal de São Paulo (UNIFESP) e na Santa Casa de Misericórdia de São Paulo. Resultados: $\mathrm{O}$ anticorpo contra Dx selecionado mostrou boa especificidade, coeficiente de variação (CV\%) intra e interensaio < 20\%, exatidão de $93,8 \%$ e dose mínima detectada de 19,5 ng/dl. A concentração de Dx no soro foi semelhante nos voluntários e pacientes com SC (ausência/supressão do cortisol): 205 a $703 \mathrm{ng} / \mathrm{dl}$ e 174 a $661 \mathrm{ng} / \mathrm{dl}$ (intervalo de confiança [IC] 95\%), respectivamente; os valores foram indetectáveis naqueles que não se submeteram ao teste. Discussão: $O$ anticorpo empregado apresenta boa afinidade e especificidade para quantificar a Dx no soro. O RIE mostrou reprodutibilidade e eficiência na determinação dos níveis séricos de Dx durante o TSDx. Conclusão: $O$ presente RIE para a dosagem de Dx no soro é acurado e confiável, permitindo estabelecer uma faixa de referência de valores para subsidiar a interpretação do TSDx.

\section{abstract}

Introduction: The $1 \mathrm{mg}$ dexamethasone suppression test (DXST) is widely used to screen Cushing's syndrome (CS) due to its high diagnostic accuracy. CS is an endocrine-metabolic disorder caused by hypercorticism, which is characterized by the absence of cortisol suppression in DXST. Objective: To develop a radioimmunoassay (RIA) for the measurement of serum dexamethasone (Dx) to complement DxST. Methods: Three rabbits were inoculated with dexamethasone-21-hemisuccinate-BSA in order to choose the best antibody. Serum Dx RIA was performed according to RE 899/2003 (Agência Nacional de Vigilância Sanitária [ANVISA]) regulations. Serum samples from 96 volunteers from Universidade Federal de São Paulo (UNIFESP) and Santa Casa de Misericórdia de São Paulo were analyzed, 67 of which were submitted to DxST and 29 were not. There were 12 patients with CS. Results: The Dx antibody chosen showed good specificity. Intra- and interassay CV were < 20\% with $93.8 \%$ accuracy and the lowest detection limit was $19.5 \mathrm{ng} / \mathrm{dl}$. Serum Dx concentration was similar among both volunteers and CS patients (absence of cortisol suppression): 205 to $703 \mathrm{ng} / \mathrm{dl}$ and 174 to 661 $\mathrm{ng} / \mathrm{dl}(95 \% \mathrm{Cl})$, respectively. Values were undetectable among those that were not submitted to the test. Discussion: The anti-Dx antibody shows high specificity and reliability to quantify serum Dx in DxST. The Dx RIA presented reproducibility and reliability in the determination of serum Dx levels during DxST. Conclusion: The current RIA for serum Dx is accurate and reliable, which permits to establish a reference value range to substantiate DXST interpretation. key words

Dexamethasone

Cortisol

Radioimmunoassay

Suppression test

Cushing's syndrome

\footnotetext{
1. Biomédica.

2. Farmacêutica.

3. Farmacêutica.

4. Doutor em Medicina; professor associado de Medicina da Universidade Federal de São Paulo (UNIFESP).

5. Doutor em Medicina; professor associado de Medicina da UNIFESP.
} 


\section{Introdução}

A dexametasona (9-fluoro-11 $\beta, 17,21$-triidroxi-16 $\alpha$ metilpregn-1,4-diene-3,20-diona [Dx]) $)^{(12)}$ é um esteroide sintético com grande potência glicocorticoide (GC) empregado terapeuticamente no tratamento de inúmeras doenças de caráter inflamatório, alérgico e autoimune. Apresenta biodisponibilidade de $80 \%$ a $90 \%$, metabolização hepática e excreção essencialmente renal; seu tempo de meia-vida plasmática é de cerca de 3 horas, enquanto sua meia-vida biológica é de 36 a 56 horas $^{(9)}$.

A síndrome de Cushing (SC), descrita em 1932 pelo neurocirurgião norte-americano Harvey W. Cushing, é caracterizada por manifestações clínicas típicas, que incluem obesidade central, fraqueza muscular, hipertensão arterial, intolerância aos carboidratos, osteoporose etc. ${ }^{(18)}$. Essas manifestações se devem à exposição prolongada a quantidades excessivas de GCs circulantes, decorrentes da produção aumentada de cortisol pelas adrenais e do uso terapêutico de GCs exógenos (SC iatrogênica), sendo esta última a causa mais comum da síndrome ${ }^{(17,18)}$. A SC endógena é menos comum e resulta da produção excessiva de cortisol, quer por um tumor primário (adenoma ou carcinoma) da própria adrenal, quer pelo estímulo continuado de ambas as glândulas (hiperplasia adrenal) pela produção excessiva de hormônio adrenocorticotrofina (ACTH) por um tumor de origem hipofisária ${ }^{(16,17)}$.

A investigação laboratorial de pacientes suspeitos da SC é rotineiramente realizada em duas etapas, após a exclusão do uso de GCs exógenos pela anamnese. Na primeira, procura-se confirmar o estado de hipercortisolismo por meio de manobras que caracterizem a perda do ritmo circadiano na secreção do cortisol, sua produção excessiva e a resistência à supressão do eixo hipotálamo-hipófise-adrenal $(\mathrm{HHA})^{(13)}$; na segunda, o enfoque é direcionado para o diagnóstico diferencial das várias etiologias da $\mathrm{SC}^{(20)}$.

Como os GCs são capazes de suprimir a secreção do ACTH em indivíduos normais e não nos portadores da SC, o teste rápido (overnight) de supressão com Dx (TSDx) firmou-se como o procedimento investigativo mais amplamente empregado na primeira etapa (rastreamento e confirmação do hipercortisolismo), dada sua facilidade operacional e seu baixo custo(8, 19).

Entretanto, embora tenha elevada acurácia diagnóstica, o TSDx está sujeito a resultados imprecisos. Além da possível falha na ingestão e na absorção do produto pelo paciente, o uso de medicamentos como fenitoína, fenobar- bital, efedrina e rifampicina, por acelerar o metabolismo hepático da Dx, reduz seus níveis sanguíneos e, consequentemente, sua atividade fisiológica, possibilitando a ocorrência de resultados falsos positivos (ausência de supressão) ao teste ${ }^{(3)}$. Ao contrário, o uso de anticoncepcionais orais pode inibir o metabolismo hepático da Dx e prolongar sua meia-vida plasmática, estando potencialmente associado a resultados falsos negativos em casos limítrofes ${ }^{(10,21)}$.

\section{Objetivo}

Desenvolvimento de uma metodologia analítica confiável e sensível por radioimunoensaio (RIE) para a dosagem de Dx no soro para complementar o TSDx empregado no rastreamento da SC e subsidiar sua interpretação.

\section{Material e métodos}

\section{Radioimunoensaio da dexametasona}

Imunização: o anticorpo policlonal empregado no desenvolvimento do RIE foi obtido no Setor de Endocrinologia do Grupo Fleury-Medicina Diagnóstica, após imunização de três coelhos com o conjugado dexametasona-21-hemissuccinato-BSA (Steraloids, Wilton, NH, EUA), por meio de múltiplas injeções intradérmicas, sendo feitas duas aplicações, uma a cada 45 dias.

Especificidade: a especificidade do anticorpo foi testada contra os seguintes esteroides naturais e sintéticos: cortisol, cortisona, 6 $\beta$-hidrocortisona, corticosterona, 11-deoxicortisol, progesterona, 17 $\alpha$-hidroxiprogesterona, testosterona, estradiol, betametasona, prednisona e prednisolona.

Curva-padrão: foi definida a partir da diluição do padrão de Dx (adquirido da Sigma-Aldrich, São Paulo, Brasil), preparado em solução etanólica, na concentração de $1 \mathrm{mg} / \mathrm{ml}$. As concentrações 39, 78, 156, 312, 625, 1.250, $2.500 \mathrm{e}$ $5.000 \mathrm{ng} / \mathrm{dl}$ foram preparadas em tampão fosfato-gelatina (TFG) pH 7. O procedimento baseia-se na adição de: (1) $50 \mu$ le cada ponto da curva-padrão, dos controles $(78,312$ e $2.500 \mathrm{ng} / \mathrm{dl}$ ) e dos soros, todos em duplicata; (2) $100 \mu \mathrm{l}$ do anticorpo anti-Dx, utilizado na diluição 1:1.500 em TFG; (3) $100 \mu$ l do esteroide triciado $(6,7-3 \mathrm{H}[\mathrm{N}]$-dexamethasone, PerkinElmer, EUA), com atividade específica de 1,3653 TBq/ mmol, utilizado em uma contagem de $5.000 \mathrm{cpm}$; (4) $450 \mu \mathrm{l}$ de TFG. 
O volume final e o tempo de incubação foram respectivamente de $700 \mu \mathrm{l}$ e 12 a 16 horas a $4^{\circ} \mathrm{C}$; a separação foi feita pela adição de $200 \mu \mathrm{l}$ de carvão-dextran mantido em agitação contínua a $4^{\circ} \mathrm{C}$ e pipetados em todos os tubos para adsorção do esteroide triciado não ligado ao anticorpo ${ }^{(24)}$. Em seguida, as amostras foram centrifugadas a $3.000 \mathrm{rpm}$ por 5 minutos a $4^{\circ} \mathrm{C}$, o sobrenadante foi decantado para tubo plástico contendo líquido de cintilação (Opthfase "Hisafe" 3, PerkinElmer, EUA) e a contagem foi realizada em um contador de radiação beta (Analyzer-Tri-Carb 2100 TR Packard, EUA). O cálculo da Dx, em ng/dl, foi realizado com o auxílio do software RIACAL (WallacOy, Turku, Finlândia).

\section{Validação do RIE}

Os estudos de linearidade, limite de detecção, precisão, exatidão, reprodutibilidade, sensibilidade e estabilidade foram realizados de acordo com as normas vigentes da Agência Nacional de Vigilância Sanitária (ANVISA) (RE $899 / 2003)^{(5)}$.

Para o estudo da linearidade foram avaliadas, em quintuplicata, amostras preparadas a partir do padrão de Dx na faixa de concentração de 39 a $5.000 \mathrm{ng} / \mathrm{dl}$. Essas concentrações contemplam a faixa de trabalho para aplicação diagnóstica. O limite de detecção (LD) ou dose mínima detectada (menor concentração de Dx presente em uma amostra) foi determinado a partir do coeficiente de variação (CV\%) da quintuplicata de soluções de concentrações conhecidas e decrescentes (39; 19,5; 9,6; 4,8 e 2,4 ng/dl).

A precisão intraensaio foi avaliada pelo $\mathrm{CV} \%$ médio da quintuplicata das amostras de oito diferentes concentrações $(39,78,156,312,625,1.250,2.500$ e $5.000 \mathrm{ng} / \mathrm{dl})$ analisadas 12 vezes no mesmo dia. A reprodutibilidade foi avaliada pelo CV\% médio interensaio, no qual foram analisadas três diferentes concentrações $(78,312$ e $2.500 \mathrm{ng} / \mathrm{dl})$ por 13 ensaios consecutivos. A exatidão do método foi verificada pela análise de amostras em concentrações conhecidas (39, $78,156,312,625,1.250,2.500$ e $5.000 \mathrm{ng} / \mathrm{dl}$ ) e expressa em porcentagem.

Para o estudo de estabilidade realizou-se o teste de curta duração, que consistiu na avaliação em quintuplicata de três amostras $(78,312$ e $2.500 \mathrm{ng} / \mathrm{dl}$ ) recém-preparadas e expostas à temperatura ambiente por 4 horas.

Os valores da concentração sérica de Dx foram definidos entre os percentis 2,5 e 97,5 dos voluntários submetidos ao TSDx com $1 \mathrm{mg}$. Os resultados são apresentados como média \pm desvio padrão (DP) e mediana e intervalo de confiança (IC) de $95 \%$.

\section{Dosagem do cortisol}

Para a determinação do cortisol sérico utilizou-se um RIE empregado há mais de 30 anos na rotina do nosso laboratório(23).

\section{População estudada}

Foram analisadas no presente estudo amostras de soro de 96 indivíduos-controles e voluntários, sendo 67 mulheres (M) e 29 homens (H), com idades entre 20 e 75 anos (mediana de 50 anos); 67 deles $(42 \mathrm{M} / 25 \mathrm{H})$ foram submetidos ao TSDx e os 29 restantes $(25 \mathrm{M} / 4 \mathrm{H})$ não. Nenhum desses indivíduos relatava o uso de medicamentos à base de corticosteroides, esteroides sexuais ou outros produtos que pudessem potencialmente interferir nas dosagens hormonais, no funcionamento do eixo $\mathrm{HHA}$ ou no metabolismo da Dx.

O TSDx também foi empregado em 12 pacientes $(10 \mathrm{M} / 2 \mathrm{H})$ com diagnóstico confirmado de SC com idades entre 27 e 71 anos (mediana de 47 anos), acompanhados no Ambulatório de Adrenal da Disciplina de Endocrinologia da Universidade Federal de São Paulo (UNIFESP) e na Santa Casa de Misericórdia de São Paulo.

\section{Teste oral de supressão com dexametasona}

Os pacientes e voluntários que se submeteram ao TSDx foram instruídos a ingerir $1 \mathrm{mg}$ de Dx (dois comprimidos de $0,5 \mathrm{mg}$ de Decadron ${ }^{\circledR}$, Aché, São Paulo, fornecidos sem custo aos indivíduos) às 23 horas e comparecer ao Laboratório de Esteroides da Disciplina de Endocrinologia da UNIFESP na manhã seguinte, entre 8 e 9 horas, em jejum, para a coleta de sangue venoso periférico para dosagem de Dx e cortisol. Os voluntários que não se submeteram ao TSDx tiveram amostras basais coletadas no mesmo horário.

O termo de consentimento informado foi obtido de todos os participantes após explanação detalhada do estudo previamente aprovado pelo Comitê de Ética em Pesquisa da Escola Paulista de Medicina (EPM) da UNIFESP $\left(n^{\circ} .2174 / 08\right)$.

\section{Resultados}

\section{Radioimunoensaio da dexametasona}

Os três animais imunizados produziram anticorpos contra a Dx, sendo escolhido o de melhor título e 
especificidade, designado Dexa3. O estudo de especificidade desse anticorpo contra os principais esteroides naturais e sintéticos mostrou reatividade cruzada inferior a $1 \%$ para todos eles (Tabela 1). A diluição do anticorpo Dexa3, que proporcionou porcentagem de ligação ideal $\left(B_{0}\right)$ entre $25 \%$ e 35\%, foi de 1:1.500 em TFG.

Reatividade cruzada do anticorpo Dexa3 com os vários esteroides naturais $\mathrm{e}$

Tabela 1 sintéticos testados

$\begin{array}{lc}\text { Esteroide } & 100 \\ \text { Dexametasona } & 0,67 \\ \text { Betametasona } & 0,72 \\ \text { Prednisolona } & 0,39 \\ \text { Cortisol } & 0,05 \\ 17 \alpha \text {-hidroxiprogesterona } & <0,04 \\ \text { Cortisona } & <0,04 \\ \text { Corticosterona } & <0,04 \\ \text { 6- } \beta \text {-hidrocortisol } & <0,04 \\ \text { 11-desoxicortisol } & <0,04 \\ \text { Prednisona } & <0,04 \\ \text { Testosterona } & <0,04 \\ \text { Progesterona } & <0,04 \\ \text { Estradiol } & \end{array}$

Observou-se linearidade altamente significativa $(p<0,001)$ na faixa de concentração estudada de 39 a $5.000 \mathrm{ng} / \mathrm{dl}$, com coeficiente de determinação $\left(r^{2}\right)$ igual a 0,9937 (Figura 1).

No estudo de variação intraensaio, realizado com os oito pontos da curva-padrão, o CV\% obtido foi sempre menor do que 15\%, conforme se observa na Figura 2.

O CV\% interensaio, estudado com três pontos distintos da curva $(78,312$ e $2.500 \mathrm{ng} / \mathrm{dl})$, também mostrou resultados satisfatórios, abaixo de 17\% (Figura 2). No estudo de estabilidade, o CV\% foi menor que $10 \%(5,9 \pm 1,5)$ em todas as concentrações testadas.

A exatidão do método foi de $93,8 \%(r=0,9988)$, variando de $75,2 \%$ (para a concentração máxima da curva - $5.000 \mathrm{ng} / \mathrm{dl}$ ) a 107,2\% (para a concentração mínima da curva - $39 \mathrm{ng} / \mathrm{dl}$ ), e a dose mínima detectada foi de $19,5 \mathrm{ng} / \mathrm{dl}$.

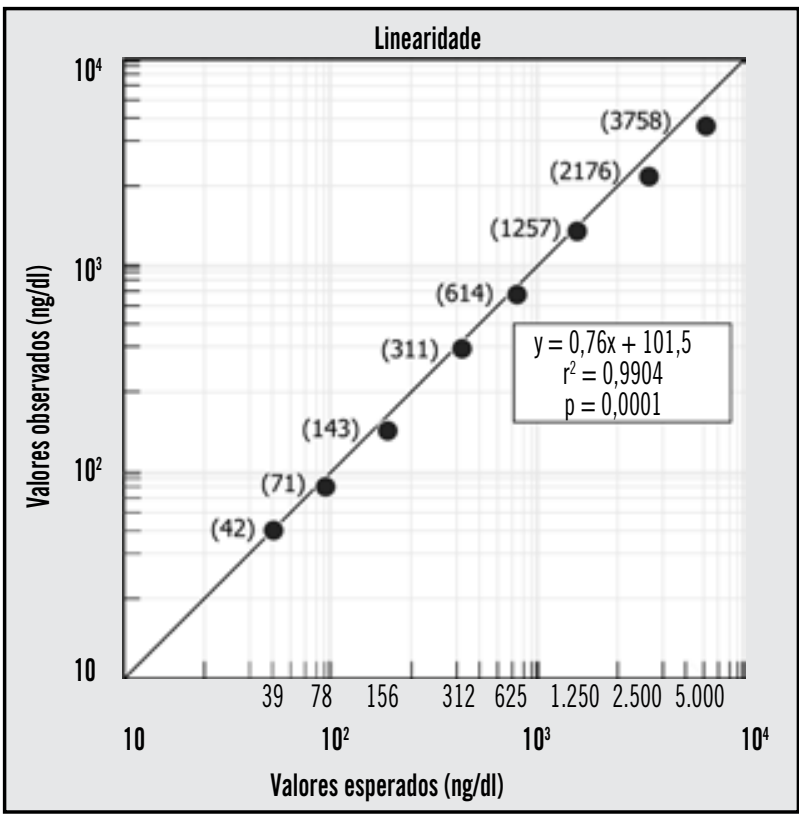

Figura 1 - Representação gráfica da linearidade do método RIE para a dosagem de Dx no soro

$R I E$ : radioimunoensaio; Dx: dexametasona.

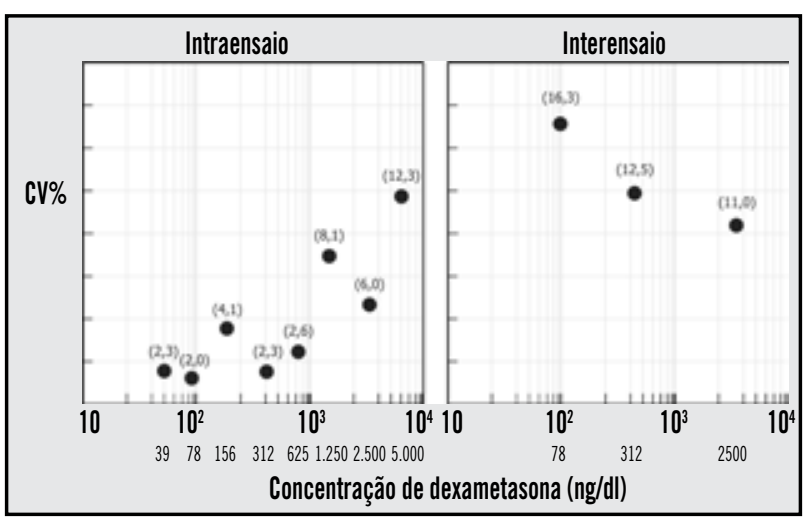

Figura 2 - CV\% intraensaio determinado com 12 pontos da curva-padrão e CV\% interensaio determinado com três pontos predefinidos da curva-padrão

CV\%: coeficiente de variação.

\section{Valores séricos de Dx e cortisol}

Os valores de Dx determinados no soro dos 67 voluntários que se submeteram ao TSDx com $1 \mathrm{mg}$ às 23 horas variaram de 205 a $703 \mathrm{ng} / \mathrm{dl}(426 \pm 114 \mathrm{ng} / \mathrm{dl})$. Todos os voluntários submetidos ao TSDx apresentaram níveis séricos de cortisol inferiores a $2,5 \mu \mathrm{g} / \mathrm{dl}(1,2 \pm 0,5 \mu \mathrm{g} / \mathrm{dl})$. Nos voluntários que não receberam Dx, obtivemos, como esperado, valores séricos inferiores à dose mínima de detecção $(19,5 \mathrm{ng} / \mathrm{dl})$. Os pacientes com SC tiveram níveis de Dx semelhantes aos da faixa obtida nos voluntários submetidos ao TSDx ( $449 \pm 157 \mathrm{ng} / \mathrm{dl})$, porém sem supressão dos níveis de cortisol sérico $(15,7 \pm 7,9 \mu \mathrm{g} / \mathrm{dl})$, caracterizando o quadro hormonal dessa condição (Tabela 2). 
Resultados da dosagem de Dx e de cortisol séricos (em média \pm DP e mediana [P2,5-P97,5]) nos voluntários submetidos ao TSDx com $1 \mathrm{mg}$ de Dx, nos controles que não receberam Dx e nos

Tabela 2 pacientes com diagnóstico confirmado de SC

\begin{tabular}{lcc}
\hline Indivíduos estudados & Dexametasona $(\mathrm{ng} / \mathrm{dl})$ & Cortisol $(\mu \mathrm{g} / \mathrm{dl})$ \\
\hline Controles submetidos ao TSDx $(n=67)$ & $426 \pm 144$ & $1,2 \pm 0,5$ \\
Controles que não fizeram o TSDx $(n=29)$ & $416[205-703]$ & $1,1[0,4-2,2]$ \\
\hline Pacientes com SC confirmada $(n=12)$ & $<20$ (indetectável) & Não realizado \\
& & \\
\hline
\end{tabular}

Dx: dexametasona; DP: desvio padrão; TSDx: teste de supressão com dexametasona; SC: síndrome de Cushing.

\section{Discussão}

A maior dificuldade no desenvolvimento de um sistema de RIE é a obtenção de antissoros com as características adequadas de afinidade e especificidade, indispensáveis para o desenvolvimento de um ensaio sensível e específico $^{(1,15)}$. Os resultados mostrados permitiram concluir que o anticorpo Dexa3 é eficiente e apresenta afinidade e especificidade suficientes para quantificar a Dx no soro por RIE. O antissoro Dexa3 apresentou correlação positiva e significativa $(r=0,85 ; p<0,0001)$ quando comparado com um anticorpo comercial, e a porcentagem de ligação em soros sem a presença de $\mathrm{Dx}$ foi semelhante à máxima obtida no teste de ligação. $O$ estudo de especificidade do Dexa3 contra os principais esteroides naturais ou sintéticos mostrou reatividade cruzada mínima, inferior a $1 \%$ para todos os produtos estudados.

Os estudos analíticos do presente método foram validados de acordo com a resolução RE 899/2003 da ANVISA(5). A excelente exatidão desse RIE para Dx $(93,8 \%)$ corrobora outros estudos $(2,4,11,25)$ e confere confiabilidade ao ensaio.

O RIE desenvolvido apresenta boa reprodutibilidade tanto nas extremidades inferiores como nas superiores da escala de trabalho, pois o CV\% obtido nas análises intraensaio (5,2\% a $13,2 \%)$ e interensaio (11\% a $16,3 \%)$ foi menor do que $20 \%$ para todos os pontos da curva-padrão testados, além de mostrar estabilidade adequada nas amostras expostas por até 4 horas em temperatura ambiente.

O presente método mostrou-se eficiente na determinação dos níveis séricos de Dx durante o TSDx de $1 \mathrm{mg}$, teste empregado rotineiramente na identificação de pacientes com suspeita de $\mathrm{SC}^{(22)}$. A faixa de valores encontrada para a Dx no soro dos controles submetidos ao TSDx com $1 \mathrm{mg}$, ingerido cerca de $9 / 10$ horas antes, foi de 205 a $703 \mathrm{ng} / \mathrm{dl}$ (IC 95\%). A supressão do eixo HHA foi constatada em todos pelo encontro de níveis séricos de cortisol abaixo de 2,5 $\mu \mathrm{g} / \mathrm{dl}(6,7,14)$. Apesar de o valor mínimo de Dx encontrado no soro dos controles (selecionados por não estarem sob uso de medicamentos que conhecidamente pudessem interferir no teste) ter sido de $147 \mathrm{ng} / \mathrm{dl}$, a possibilidade de que níveis mais baixos possam também estar associados à supressão normal dos níveis de cortisol (abaixo de 2,5 $\mu \mathrm{g} / \mathrm{dl}$ ) não está descartada. Contudo, níveis de Dx abaixo daquele valor mais frequente estarão associados à possibilidade de resultados falsos positivos.

Nos indivíduos que não se submeteram ao TSDx, os valores de Dx no soro foram sistematicamente indetectáveis (abaixo de $20 \mathrm{ng} / \mathrm{dl}$ ). Assim, o encontro de valores nessa faixa, em indivíduos que são submetidos ao TSDx para diagnóstico da SC, caracteriza a falta de ingestão ou de absorção do medicamento, invalidando o teste.

Os valores de Dx observados nos pacientes com SC mostraram-se praticamente idênticos àqueles encontrados nos indivíduos-controles, sem a devida supressão dos valores de cortisol, típica da doença. Esse fato sugere que o hipercortisolismo endógeno per si e/ou outras alterações metabólicas presentes na SC parecem não interferir significativamente na absorção e/ou no metabolismo da Dx. No indivíduo com forte suspeita clínica de SC, valores séricos de Dx abaixo do limite observado recomendam a repetição do teste.

Conclui-se que o presente RIE desenvolvido para a dosagem de Dx no soro é acurado e confiável, apresentando valores semelhantes após a realização do TSDx de $1 \mathrm{mg}$ em indivíduos-controles e pacientes com SC, permitindo estabelecer uma faixa de referência para subsidiar a interpretação do teste de maneira mais fidedigna. 


\section{Referências}

1. AlBUQUERQUE, R. H. Controle de qualidade em radioimunoensaio. Arq Bras Endocrinol Metabol, v. 25, p. 120-24, 1981.

2. Beltran, M. P.; NOGUeIRA, G. P. Validação de radioimunoensaio para quantificação de leptina plasmática bovina. Braz J Vet Res Anim Sci, v. 47, n. 1, p. 5-12, 2010.

3. BOSCARO, M. A. E. et al. Cushing's syndrome. Lancet, v. 357, p. 783-91, 2001

4. BOWSHER, R. R.; WOLNY, J. D.; FRANK, B. H. A rapid and sensitive radioimmunoassay for the measurement of proinsulin in human serum. Diabetes, v. 41, p. 1084-90, 1992.

5. BRASIL. Agência Nacional de Vigilância Sanitária. Resolução $n^{\circ} 899$, de 29 de maio de 2003. Consulta pública, 2010. Disponível em: <http: www.anvisa.gov. br>. Acesso em: 16 jan. 2010.

6. CARROLL, B. J. et al. Plasma dexamethasone concentrations and cortisol suppression response in patients with endogenous depression. J Clin Endocrinol Metab, v. 51, n. 3, p. 433-37, 1980.

7. FINDLING, J. W.; RAFF, H.; ARON, D. C. The low-dose dexamethasone suppression test: a reevaluation in patients with Cushing's syndrome. J Clin Endocrinol Metab, v. 89, p. 1222-6, 2004.

8. FRIEDMAN, T. C. An update on the overnight dexamethasone suppression test for the diagnosis of Cushing's syndrome: limitations in patients with mild and/or episodic hypercortisolism. Exp Clin Endocrinol Diabetes, v. 114, n. 7, p. 356-60, 2006.

9. GRIES, D. et al. A single dose of intramuscularly administered dexamethasone acetate is as effective as oral prednisolone to treat asthma exacerbation in young children. J Pediar, v. 136, p. 298-303, 2000.

10. GUSTAVSON, L. E.; BENET, L. Z. Pharmacokinetics of natural and synthetic glucocorticoids. In: ANDERSON, D. C.; WINTER, J. S. D. (Ed.). The adrenal cortex. Stoneham, Mass: Butterworth Publishers, 1985. p. 235-79.

11. HAMPTON, S. M. et al. A direct assay for proinsulin in plasma and its applications in hypoglycaemia. Clin Endocrinol, v. 29, p. 9-16, 1988.

12. INTERNATIONAL UNION OF PURE AND APPLIED CHEMISTRY (IUPAC). Nomenclature of steroids. Pure \& Appl Chem, v. 61, n. 10, p. 1783-822, 1989.
13. KATER, C. E. et al. Determinação do cortisol sérico por radioimunoensaio e sua aplicação no diagnóstico da síndrome de Cushing. Arq Bras Endocrinol Metabol, v. 23, n. 4, p. 155-65, 1979.

14. LO, J. C.; TYRREL, J. B.; WILSON, C. W. Corticotroph adenomas. In: THAPAR, K. et al. (Ed.). Diagnosis and management of pituitary tumors. New Jersey: Human Press, 2001. p. 317-32.

15. MIDGLEY, A. R.; NISWENDER, G. D.; REBAR, R. W. Principles for the assessment of the reliability of radioimmunoassay methods (precision, accuracy, sensitivity, specificity). Acta Endocrinol, v. 142, p. 163-84, 1969.

16. NEWELL-PRICE, J. et al. Cushing's syndrome. Lancet, v. 367, p. 1605-17, 2006.

17. NEWELL-PRICE, J. et al. The diagnosis and differential diagnosis of Cushing's syndrome and pseudo-Cushing's states. Endocr Rev, v. 19, p. 647-72, 1998.

18. ORTH, D. N. Cushing's syndrome. N Eng/ J Med, v. 332, p. 791-803, 1995.

19. RITCHIE, J. C. et al. Plasma cortisol determination for the dexamethasone suppression test. Arch Gen Psychiatry, v. 42, p. 493-97, 1985.

20. ROLLIN, G. A. F. S.; CZEPIELEWSKI, M. A. Síndrome de Cushing: é possível simplificar e padronizar sua abordagem diagnóstica? Arq Bras Endocrinol Metab, v. 47, n. 4, p. 368-80, 2003.

21. TSAY, S. Y. et al. Molecular interactions of steroid hormone receptor with its enhancer element: evidence for receptor dimmer formation. Cell, v. 55, p. 361-69, 1988.

22. VIEIRA, J. G. H. et al. Estudo do valor do teste rápido de supressão com dexametasona na triagem de pacientes suspeitos de síndrome de Cushing. Rev Ass Med Brasil, v. 31, n. 7/8, p. 129-32, 1985.

23. VIEIRA, J. G. H. et al. Método radioimunológico para a dosagem do cortisol sérico. Rev Bras Patol Clin, v. 15, n. 3, p. 125-30, 1979.

24. VIEIRA, J. G. H. et al. Radioimunoensaio da 17-hidroxiprogesterona no soro: considerações metodológicas. Arq Bras Endocrinol Metab, v. 24, n. 1, p. 24-30, 1980.

25. YOSHIOKA, N. et al. Serum proinsulin levels at fasting and after oral glucose load in patients with type 2 (noninsulin-dependent) diabetes mellitus. Diabetologia, v. 3, n. 6, p. 355-60, 1988.

\begin{tabular}{l|l} 
& Endereço para correspondência \\
\hline & Claudio E. Kater \\
& Laboratório de Esteroides \\
Disciplina de Endocrinologia, Departamento de Medicina \\
Universidade Federal de São Paulo/Escola Paulista de Medicina \\
Rua Pedro de Toledo, 781 - $13^{\circ}$ andar \\
CEP: 04039-032 - São Paulo-SP \\
e-mail: kater@unifesp.br
\end{tabular}

